\title{
THROMBOLYTIC THERAPY IN BILATERAL EMBOLISM OF RENAL ARTERIES BRANCHES
}

\author{
MARCELO F. CASSINI, PATRÍCIA L. CASSINI, RODRIGO L. RUSSO \\ Section of Urology, Internal Medicine, and Intensive Care, Santa Casa de Misericórdia, \\ São Sebastião do Paraíso, Minas Gerais, Brazil
}

\begin{abstract}
Bilateral renal artery embolism is rare, but it is a significant cause of arterial hypertension and renal failure, and most often is associated with cardiac arrhythmias. We report a case of bilateral renal artery embolism with a satisfactory outcome following use of thrombolytic therapy.

A 42 year-old Caucasian man presented a sudden complaint of intense abdominal pain, in mesogastrium and left flank with dorsal irradiation, 3 days after electrical cardioversion due to cardiac arrhythmia. Laboratory tests revealed slight leukocytosis, hematuria, and creatinine of 1.8 $\mathrm{mg} / \mathrm{dL}$. Chest radiography was normal and computerized tomography showed an area of massive ischemia in left kidney, and focal ischemia in right kidney and spleen.

The patient was then submitted to systemic venous therapy with 1.5 million units of streptokinase, with an excellent outcome.
\end{abstract}

Key words: kidney; renal artery; embolism; therapeutics; thrombolytics

Int Braz J Urol. 2003; 29: 147-8

\section{INTRODUCTION}

Bilateral acute occlusion of renal artery is rare, but it is a significant cause of renovascular systemic hypertension and renal failure. In most cases it is associated to cardiac diseases, particularly arrhythmias (55\% atrial fibrillation) (1), and can occur also in blunt trauma, renal artery stenosis, iatrogenic angiographic manipulation, cocaine injection, use of intra-aortic balloon, among others.

The purpose of this work is to report a case of bilateral acute renal embolic ischemia with excellent outcome following systemic thrombolytic therapy.

\section{CASE REPORT}

A 42 year-old Caucasian man was admitted in hospital (3 days after release from an electrical cardioversion due to atrial fibrillation), presenting intense abdominal pain for 1 hour, with sudden onset, in mesogastrium and left flank with dorsal irradiation, associated with profuse sweating, psychomotor agitation, abdominal distension, vomiting and oliguria. The abdomen was diffusely painful during palpation, without signs of peritoneal irritation. Cardiac rhythm was regular and sinus. Laboratory tests revealed slight leukocytosis, with urinalysis showing hematuria (+++), creatinine of $1.8 \mathrm{mg} / \mathrm{dL}$ and blood urea nitrogen of $90 \mathrm{mg} / \mathrm{dL}$. Chest and abdomen radiographies were normal.

The abdominal computerized tomography (CT) revealed the presence of a large ischemic area in left kidney, as well as an area without perfusion in the upper pole of the right kidney, and focal ischemia in spleen (Figure-1). Echocardiogram revealed no intracavitary thrombus.

The patient received 1,500,000 IU of intravenous Streptokinase, due to hospital limitations to perform selective intra-arterial thrombolytic therapy, 


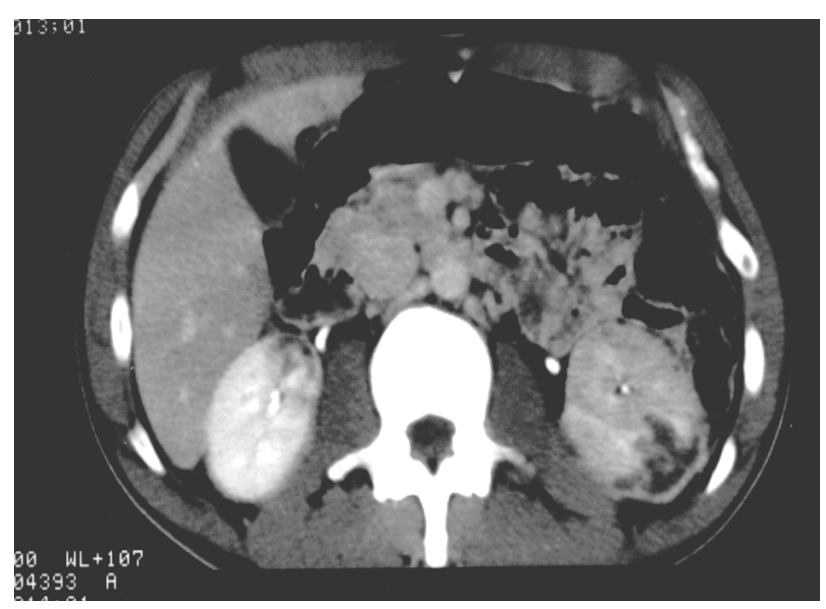

Figure 1 - Abdominal computerized tomography with venous contrast revealing diffuse filling defects in left kidney and areas of focal ischemia in right kidney.

followed by full heparinization and analgesia, with a good outcome, with restoration of diuresis. Hematuria subsided in the fifth day and the patient was released in the tenth day, with serum creatinine of $1.2 \mathrm{mg} / \mathrm{dL}$, using warfarin sodium $5 \mathrm{mg} / \mathrm{d}$ and amiodarone $200 \mathrm{mg} / \mathrm{d}$.

A new abdominal CT, performed 5 months later, showed total reperfusion of renal ischemic areas with a small residual infarct lesion in the spleen (Figure-2). Currently, the patient keeps an outpatient follow-up, is assymptomatic, normotense and with creatinine of $1.0 \mathrm{mg} / \mathrm{dL}$.

\section{DISCUSSION}

Clinical manifestations of uni- or bilateral renal artery embolism are unspecified and inconsistent, and that is why the diagnosis can take some time to be made (2). It must be always considered in cases of intense and sudden abdominal pain in patients with a history of cardiac arrhythmias or valvar disease. Mesenteric thrombosis must be excluded.

The diagnosis is confirmed by CT or renal arteriography, and currently the first-choice treatment, for embolism either in renal arteries or in one of their branches, is selective intra-arterial thrombolytic therapy (streptokinase), within a period lower than 3 hours from the initial symptoms $(2,3)$. In case of delayed diagnosis, anticoagulation is used, even though procedures

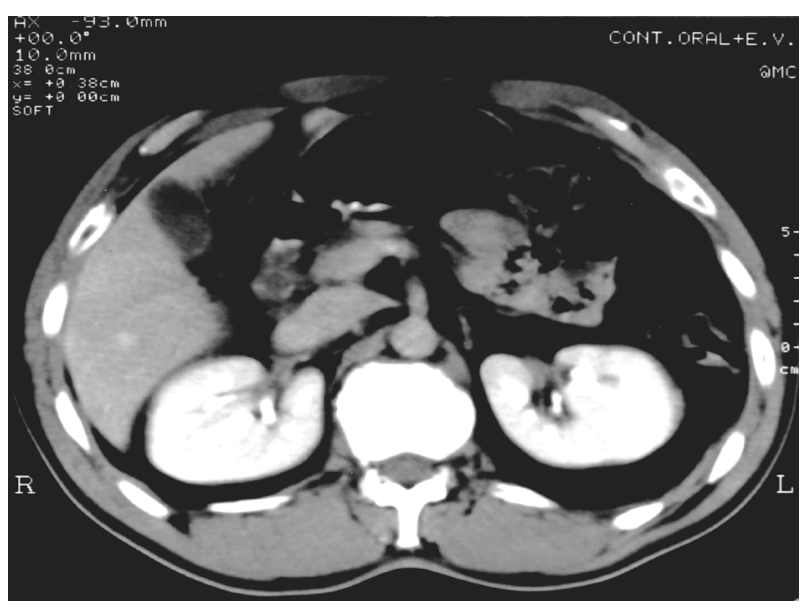

Figure 2 - Abdominal computerized tomography with venous contrast, performed 5 months after thrombolytic therapy, revealing total reperfusion of both kidneys.

such as embolectomy and more aggressive surgeries (autotransplantation, aortorenal bypass) remain as a therapeutical option as well, in specialized centers, but with higher morbidity and mortality (3).

\section{REFERENCES}

1. Blum U, Billmann P, Krause T, Gabelmann A, Keller E, Moser E, et al.: Effect of local low dose thrombolysis on clinical outcome in acute embolic renal artery occlusion. Radiology 1993; 189:549-54.

2. Gasparini M, Hoffman R, Stoller M: Renal artery embolism: Clinical features and therapeutic options. J Urol. 1992; 147:567-72.

3. Morris D, Kisly A, Stoyka CG, Provenzano R: Spontaneous bilateral renal artery occlusion associated with chronic atrial fibrillation. Clin Nephrol. 1993; 39:257-9.

Received: October 10, 2002 Accepted after revision: March 12, 2003

\author{
Correspondence address: \\ Dr. Marcelo Ferreira Cassini \\ Av. Afonso Pena, 400 \\ São Sebastião do Paraíso, MG, 37950-00, Brazil \\ Fax: + 5535 3531-3175 \\ E-mail: cassini@paraisonet.com.br
}

